C 107

\title{
数値解析によるヒ一ビング運動する弾性翼後流の渦流れ構造
}

\author{
永田 哲志（九工大院），判脇 正樹（九工大），田中 和博（九工大）
}

\section{Numerical Simulation of Vortex Flow Structure behind a Heaving Elastic Airfoil}

\author{
Tetsushi NAGATA, Masaki FUCHIWAKI and Kazuhiro TANAKA
}

\begin{abstract}
A flow field around moving elastic airfoil has attracted significant attentions in recent years. A flow around an elastic body is treated as a coupled problem of a fluid and a structure. However, impacts of elasticity on a flow field and differences from a flow field in the wake of a rigid airfoil have not been clarified yet. The purpose of the present study is to perform the fluid-structure interaction analysis using ANSYS 11.0 and ANSYS CFX 11.0 and is to clarify the wake structure.
\end{abstract}

Keywords : Elastic airfoil, Vortex, Unsteady flow, Numerical simulation

\section{1. 緒 論}

低レイノルズ数領域における非定常運動寸る翼まわり の流れ場およびその非定常流体力特性に閣する研究は凨 体翼を中心に進められてきた。しかしながら，最近では， 弹性運動翼まわりの流れ場およびその非定常流体力特性 が注目されている，弾性運動翼まわりの流れ場纺，流体 檴造連成問題（Fluid-Structure-Interaction, FSI) とし て取り扱われており，物体の大きな変形とその流れ場と の相互作用が大きな強連成問題（双方向連成）であるた め，その流れ場および非定常流体力特性は十分に明らか にされていない.

本研究では, ANSYS 11.0 および ANSYS CFX 11.0 を用い，弾性を有するヒービング運動翼まわりの流れ場 の流体構造連成解析を実現し, 弾性翼後流に形成される 渦流れおよび翼後流に形成される增速流を㓮体翼と比較 し，弾性が流れ場に与える効果を明らかにする。

\section{2. 解析対象および解析条件}

流体構造連成解析の流体部の支配方程式は，連続の式 およびNavier-Stokes方程式であり，その離散化手法に は，有限体積法を用いる、構造部の支配方程式の離散化 手法には有限要素法を用いる。

解析領域は，翼弦長cを基淮に，翼前縁，翼後縁，翼 スパン方向奥行きおよび翼面に鉛直方向の長さを，それ ぞれ $2 \mathrm{c} ， 5 \mathrm{c} ， \mathrm{c} / 12$ および $3 \mathrm{c}$ で与える。流入境界に主 流 $0.067[\mathrm{~m} / \mathrm{s}]$ を与え，流出境界を大気压解放とした。
Table 1 Analysis conditions.

\begin{tabular}{|c|c|c|c|}
\hline $\mathrm{Re}$ & $4 \times 10^{3}$ & Turbulence & $\mathrm{k}^{*} \omega$ \\
\hline $\mathrm{St}$ & 0.64 & $\mathrm{y}+$ & $<1$ \\
\hline Mesh & Hexa & Cycle & 5 \\
\hline Nodes(Fluid) & $2.1 \times 10^{5}$ & Time steps & $0.01[\mathrm{~s}]$ \\
\hline Nodes(Airfoil) & $1.0 \times 10^{4}$ & Cal. Time & 10 days \\
\hline
\end{tabular}

また，壁面境界はすべて対称境界とし，翼面には圧力と 变位デー夕を転送する境界面を定議する，その他の解析 条件を表 1 に示す。供試翼形状は NACA0010 であり, 弹性翼のヤング率およびポアンン比はそれぞれ $E=0.32$ [MPa] および $v=0.45$ である. 翼前縁から c/4 の位温 にヒービング運動を与え, 翼後縁最大振幅を基準とした ストロハル数 St を定義する。

\section{3. 解析結果および考察}

$S t=0.64$ のヒービング運動を゙行う判体翼拉よび弾性 巽まわりの等渦度線図をそれぞれ図 1 および 2 に示す。 また，PIV 解析結果および数値解析結果をそれぞれ図 （a）および (b)に示す．いずれもヒービング運動が運動 中心の位置における瞬時値を示す。

いずれの数值解析結果も PIV 解析結果とよく一致し ており，特に，流体構造連成解析も害現できていると言 える. また，弹性巽後緣加ら巻き上がる渦（図2(b)) は， 哃体翼（図1(b)）に比べて大きく成長し，その中心付近 


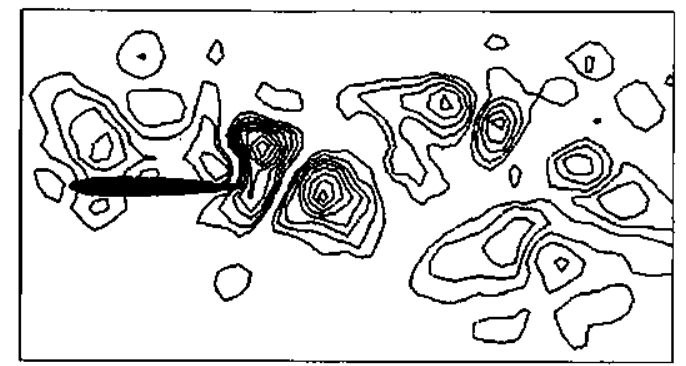

(a) PIV measurement result

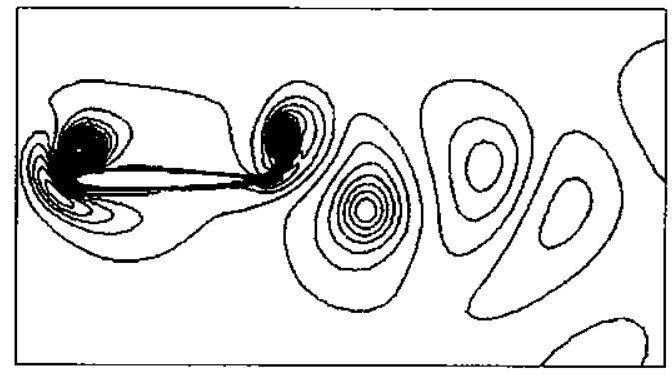

(b) Numerical simulation result

Fig.1 Vorticity contours behind heaving rigid airfoils at $\mathrm{St}=0.64$.

の渦度も大きい，そのため，翼後流に吐き出され，発達 する洞も哃体翼に比べて大きいことがわかる，さらには， 甽体翼後方の推進力発生渦列は，弹性翼に比べて密に形 成されていることがわかる．弾性翼では，ヒービング運 動とその弹性変形により翼面上で成長した渦が常に, ヒービング運動の上死点および下死点において翼後縁か ら離れるために渦間隔が大きくなる。

ヒービング運動する運動翼一弦長後方の増速流の一周 期平均を図 3 に示す. 実線および破線はそれぞれ数值解 析結果および PIV 計測結果を示し，また，のおよびメ はそれぞれ弾性翼およひ威体翼の結果を示す。

数值解析結果は，定量的には多少違いがあるものの， 定性的にはPIV 計測結果とよく一致している．弹性翼後 方の增速流は，主流に対して，ほぼ対称の分布となるが， 剛体巽後方には，大きな減速流が発生し，主流方向に対 して非対称な分布となることがいずれの結果からもわか る. 甽体翼後流に形成される推進力発生渦列が密に形成 され，翼後縁から巻き上がる渦の干涉が強くなるためで ある(1)(2)，弹性翼で仗，図 2 に示寸上うに，ヒービング 運動の上死点および下死点において翼後緣から渦が離れ るために，渦閒隔が大きくなり渦同士の干涉が小さく， そのため弾性翼後方の増速流は，主流に対して対称とな ることがわかった。

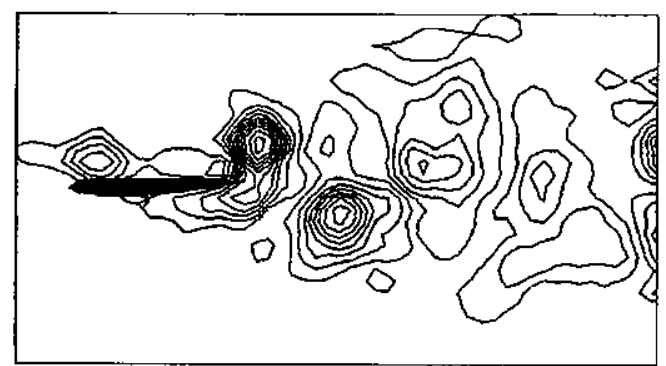

(a) PIV measurement result

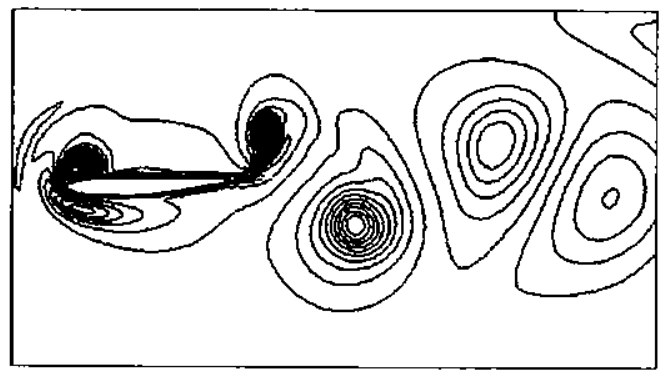

(b) Numerical simulation result

Fig.2 Vorticity contours behind heaving elastic airfoils at $\mathrm{St}=0.64$.

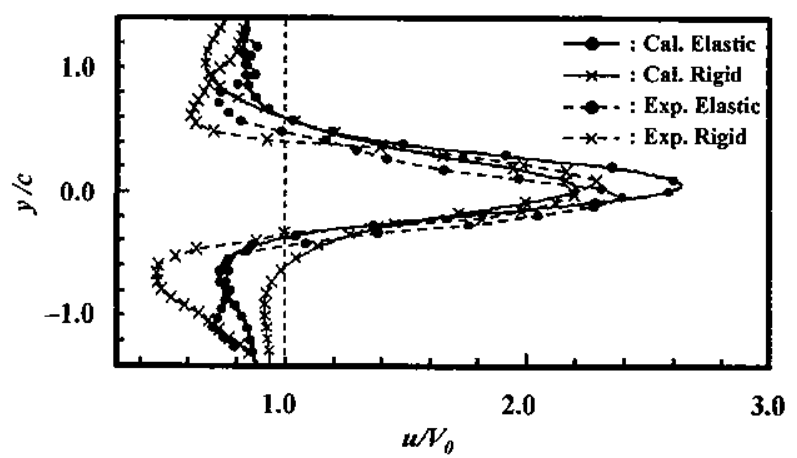

Fig.3 Mean velocity profiles during one cycle behind heaving airfoils at $\mathrm{St}=0.64$.

\section{4. 結 論}

ANSYS 11.0 および ANSYS CFX 11.0 により，ヒー ビング運動する弾性翼まわりの流体楧造連成解析を実現 した. ヒービング運動する弾性翼は，ヒービング運動と その弾性変形により翼面上で成長した渦が，常にヒービ ング運動の上死点および下死点において翼後縁から離れ る.そのため，渦間隔が大きく洞同士の干涉が小さいた めに，翼後方の增速流は，主流に対して対称に分布する.

\section{参考文献}

1) 㴊脇 他, 機碖 $\mathrm{B}, 73-728(2007)$ pp. 922

2) Lai J.C.S.,et al, AJAA Journal, Vol.37, No. 12, (1999) ppl529 